\title{
Efecto de la aplicación de inóculos microbianos sobre las características fermentativas, estabilidad aeróbica y consumo voluntario de ensilaje de gramíneas tropicales naturalizadas ${ }^{1}$
}

\author{
Carlos Rosario ${ }^{2}$, Abner A. Rodríguez $3^{3^{*}}$ y Paul F. Randel ${ }^{4}$
}

J. Agric. Univ. P.R. 97(1-2):33-56 (2013)

\begin{abstract}
RESUMEN
Se realizaron dos experimentos para determinar el efecto de la aplicación de dos inóculos de bacterias productoras de ácido láctico (BAL), sobre las características fermentativas, estabilidad aeróbica (EA) y consumo voluntario (CV) de ensilaje de gramíneas tropicales naturalizadas (GTN). Antes de ensilarse, a las GTN se les trató o no con el inóculo correspondiente, aplicado a razón de $10^{6}$ ufc/g de materia fresca para el Inóculo Comercial 1 y $10^{10} \mathrm{ufc} / \mathrm{g}$ de materia fresca para el Inóculo Comercial 2. Se aplicaron los inóculos a porciones pesadas de GTN, manualmente mezcladas, y se envasaron en silos PVC de laboratorio para determinar las características fermentativas. Se analizaron ensilajes de cada tratamiento luego de siete períodos de fermentación $(0,4,7,14,21,28, y$ $35 \mathrm{~d}$ ) para $\mathrm{pH}$ y contenidos de productos de fermentación (ácidos orgánicos y amoníaco). Para la determinación de la EA, se abrieron silos por triplicado por cada tratamiento después de $\mathbf{3 5}$ días de ensilamiento; se colocaron muestras de ensilaje en recipientes de poliestireno envueltos parcialmente con bolsas de plástico y se expusieron al aire durante cinco días. Usando termómetros incrustados en la superficie del ensilaje expuesto, se tomaron lecturas de la temperatura cada seis horas durante los cinco días; el pH se determinó después de $0,1,3$, y 5 d de exposición aeróbica. Para uso en las pruebas de CV, las GTN se fermentaron, con o sin el inóculo de BAL correspondiente, durante 35 días en bolsas de plástico de 208 L (55 galones) de capacidad. Para cada prueba se alimentaron seis ovinos criollos tipo carne, tres de ellos con cada una de las dos dietas experimentales, durante cinco días. Las dietas tenían en común $50 \%$ de heno de GTN y $50 \%$ de GTN fermentada con o sin adición de $B A L$, y se ofrecieron diariamente a $3 \%$ del peso vivo en base seca (PV/BS). Ninguno de los dos inóculos de BAL añadidos logró mejorar las características fermentativas de las GTN, las cuales resultaron ser aceptables en los ensilajes control. En ambos experimentos, los ensilajes con y sin inóculo fueron estables a condiciones aeróbicas durante cinco días. Se observó un efecto positivo de la inoculación con Inóculo Comercial 1 sobre el CV, en el primer experimento, pero no así con el Inóculo Comercial 2 en la segunda oportunidad.
\end{abstract}

${ }^{1}$ Manuscrito sometido a la Junta Editorial el 18 de abril de 2013.

${ }^{2}$ Ex Estudiante Graduado, Departamento de Industria Pecuaria, Universidad de Puerto Rico, Recinto de Mayagüez.

${ }^{3}$ Catedrático, Departamento de Industria Pecuaria, Universidad de Puerto Rico, Recinto de Mayagüez. *Autor para Correspondencia. E-mail: abner.rodriguez3@upr.edu

${ }^{4}$ Catedrático, Departamento de Industria Pecuaria, Universidad de Puerto Rico, Recinto de Mayagüez. 
Palabras clave: Productos de fermentación, dietas experimentales, ovinos, bacterias productoras de ácido láctico

\author{
ABSTRACT \\ Effects of application of microbial inoculants on fermentation \\ characteristics, aerobic stability, and voluntary intake of silage of native \\ tropical grasses
}

Two experiments were conducted to determine the effects of two different microbial inoculants of homo-fermentative and hetero-fermentative lactic acid-producing bacteria (LAB), on the fermentation characteristics, aerobic stability (AS), and intake by sheep, of native tropical grasses (NTG). Prior to ensiling, NTG were treated or not with the inoculants, applied at $10^{6} \mathrm{cfu} / \mathrm{g}$ of fresh material for Commercial Inoculant 1 , and $10^{10} \mathrm{cfu} / \mathrm{g}$ of fresh material for Commercial Inoculant 2. Treatments were applied to weighted portions of NTG, manually mixed, and packed into PVC laboratory silos. To evaluate fermentation characteristics, silage samples from each treatment were analyzed at seven ensiling periods $(0,4,7,14,21,28$, and 35 days) to determine $\mathrm{pH}$ and fermentation products (organic acids and $\mathrm{NH}_{3}-\mathrm{N}$ ). For AS determination, triplicate silos from each treatment were emptied after $35 \mathrm{~d}$ of ensiling, and the silage placed in styrofoam containers lined with plastic bags, and exposed to air during five days. Temperature was monitored every six hours during the five days and $\mathrm{pH}$ was determined after $0,1,3$, and $5 \mathrm{~d}$ of aerobic exposure. To determine voluntary intake, NTG were fermented with or without the inoculant of LAB during 35 d in $208 \mathrm{~L}$ ( 55 gallon) capacity plastic bags. For each in vivo trial, six meat-type crossbred sheep were used; three fed each of two experimental diets during five days. The diets had in common $50 \%$ tropical grass hay and $50 \%$ NTG fermented with or without the LAB and were offered daily on a $3 \%$ dry matter basis (DMB) of body weight. The addition of neither of the two inoculants of LAB achieved great improvement in the fermentation characteristics of NTG, which proved acceptable in control silages. In both experiments, silages with and without inoculants were stable during five days under aerobic conditions. There was a positive effect of inoculation with Commercial Inoculant 1 on voluntary intake in the first experiment, but not with Commercial Inoculant 2 in the second trial.

Key words: Fermentation products, experimental diets, sheep, lactic acid producing bacteria

\title{
INTRODUCCIÓN
}

En regiones tropicales las características fermentativas de los forrajes conservados como ensilaje suelen no ser satisfactorias (Rodríguez, 1996; McDonald et al., 1991). Catchpoole y Henzell (citados por Martínez, 1998) y Namihira et al. (2009) reportaron que ensilajes producidos en climas tropicales se caracterizan por bajo contenido de ácido láctico (AL), alto contenido de ácido acético (AA) y pH alto. Estos resultados se deben a un bajo desarrollo de poblaciones de BAL, que no cuentan con suficiente substrato de carbohidratos solubles en agua (CSA) presente en los forrajes ensilados, a diferencia de los forrajes más usados en clima templado. Además, el proceso fermentativo de ensilamiento en climas tropicales puede malograrse debido a altas temperaturas y humedad y 
altas poblaciones de hongos, coliformes y levaduras, a diferencia de lo usual en climas templados donde predominan las BAL (McDonald et al., 1991). En el subtrópico del estado de Florida, Adesogan (2006), encontró que el maíz ensilado a $42^{\circ} \mathrm{C}$ tuvo menor concentración de AL y AA y mayor concentración de amonio y más alto $\mathrm{pH}$ que el maíz ensilado a una temperatura más fresca, argumentando que bajo estas condiciones de alta temperatura, la fermentación tiende a ser más heteroláctica que homoláctica. Muck et al. (2003) traen a colación que ensilajes hechos bajo condiciones cálidas son más propensos a sufrir una fermentación clostridial. Se han utilizado diversos inóculos microbianos, que contienen bacterias ácido lácticas, tipo homofermentativos y/o heterofermentativos, mayormente con el propósito de mejorar la fermentación y estabilidad aeróbica (EA) de ensilajes de forrajes como maíz, trigo y sorgo (Weinberg et al., 1995; Rodríguez, 1996; Ranjit y Kung, 2000; Oude Elferink et al., 2000). Si se logra el propósito de obtener las características fermentativas adecuadas al utilizar estos aditivos microbianos, en el forraje fermentado habrá una población deseable y dominante de bacterias productoras de ácido láctico (BAL), lo que ocasiona un descenso en el $\mathrm{pH}$ que evita la proliferación de microorganismos no deseados y resulta en un ensilaje estable y de calidad. Se han realizado investigaciones con inóculos bacterianos en climas templados desde mediados del siglo XX. Bryan-Jones y Carpintero et al. (citado por McDonald et al., 1991), concluyeron que la adición del inóculo en ensilaje de ryegrass (Lolium sp.), mejoró significativamente el $\mathrm{pH}$ y las características fermentativas. McDonald et al. (1991) informaron que la inoculación de pastos ensilados a una temperatura de $42^{\circ} \mathrm{C}$ resultó en una población más alta de clostridios y una concentración mayor de ácido láctico que las presentes en pastos ensilados a $20^{\circ} \mathrm{C}$. En el trópico de Puerto Rico se han realizado pocos estudios sobre la utilización de inóculos bacterianos en ensilajes. Rodríguez (1996) no pudo demostrar que el uso de un inoculante microbiano evitara el deterioro de ensilaje de sorgo forrajero al exponerse a condiciones aeróbicas. Al ensilar sorgo granífero (Sorghum bicolor), Martínez et al. (1999) añadieron un inóculo comercial de BAL a tres niveles diferentes $(0,1 \mathrm{X}$ o $2 \mathrm{X}$ la dosis recomendada) y encontraron que el inóculo a la dosis recomendada mejoró ciertas otras características, pero no la EA; tampoco se logró efecto positivo al aumentar la dosis al doble de lo recomendado. Adesogan et al. (2004) ensilaron pasto Bermuda inoculado con $P$. pentosaceus y $L$. buchneri, y observaron una mejoría en la fermentación pero no en la EA debido a una fermentación butírica. Al presente hay poca información del uso de inóculos microbianos conteniendo BAL como método para mejorar las características fermentativas de gramíneas tropicales naturalizadas (GTN) tales como hierbas guinea (Panicum maximum), johnson 
(Sorghum halepense), pangola (Digitaria decumbens) y buffel (Cenchrus ciliaris). Esta investigación se diseñó con el objetivo de evaluar el efecto de la aplicación de dos inóculos microbianos comerciales sobre las características fermentativas, EA y consumo voluntario (CV) de ensilaje de GTN.

\section{MATERIALES Y MÉTODOS}

Se realizaron dos experimentos, cada uno de los cuales constó de un trabajo de ensilamiento en el laboratorio y una prueba de CV in vivo con corderos. Se evaluaron dos productos comerciales basados en BAL homofermentativas y heterofermentativas. En el primer experimento se evaluó el Inóculo Comercial 1, un inoculante microbiano diseñado para mejorar la fermentación y reducir o evitar la descomposición de los forrajes ensilados. Contiene cepas ácido lácticas heterofermentativas y homofermentativas de $L$. buchneri, en combinación con $P$. pentosaceus. En el segundo experimento se evaluó el Inóculo Comercial 2 , compuesto por bacterias homofermentativas y heterofermentativas ácido lácticas tales como $E$. faecium, $L$. brevis y $L$. plantarum, que alegadamente ayudan a alcanzar una estabilidad óptima tanto anaeróbica como aeróbica en ensilajes de gramíneas, alfalfa, trébol, y otros forrajes. Ambos son productos en forma de polvo, dispersables en agua.

\section{Material Vegetativo}

En ambos experimentos, el material vegetativo se cosechó en predios pertenecientes a la vaquería de la Estación Experimental Agrícola (EEA) de la Universidad de Puerto Rico, localizada en el Municipio de Lajas. Las GTN utilizadas en ambos experimentos constaron mayormente de una combinación de las hierbas guinea, johnson, pangola y buffel. Las GTN utilizadas en el experimento 1 se cosecharon a 90 días de madurez, mientras que en el experimento 2 a los 60 días. Las GTN del experimento 1 se cortaron mecánicamente a $5.08 \mathrm{~cm}$ del suelo, lo que resultó en contaminación con material inorgánico (suelo), mientras en el experimento 2 se cortaron las plantas a $15.24 \mathrm{~cm}$ en un intento por reducir la recogida de suelo junto con la materia vegetal. El forraje se cortó en el mismo predio, pero en dos lugares diferentes en los dos experimentos. Antes de ensilar se trituró el forraje mecánicamente con una cortadora de forraje (New Holland serie 36$)^{5}$, para reducirlo a un tamaño teórico de 2.5

\footnotetext{
${ }^{5}$ Los nombres de compañías y de marcas registradas sólo se utilizan para proveer información específica y su uso no constituye garantía por parte de la Estación Experimental Agrícola de la Universidad de Puerto Rico, ni endoso sobre otros productos o equipo que no se mencionan.
} 
cm de largo y se asignó a uno de los dos tratamientos experimentales: (T1) sin aditivo (control), o (T2) con el inóculo comercial de BAL correspondiente, aplicado a razón de $10^{6}$ y $10^{10} \mathrm{ufc} / \mathrm{g}$ de material fresco para Inóculo Comercial 1 e Inóculo Comercial 2. El inóculo comercial se aplicó foliarmente al material vegetativo triturado. Este se mezcló manualmente con y sin el aditivo, y se ensiló en microsilos de PVC de $1.2 \mathrm{~kg}$ de capacidad. Antes de ensilarse el forraje se tomó una muestra para análisis de su contenido de materia seca (MS) mediante el secado al horno a $65^{\circ} \mathrm{C}$ por 48 horas. Los contenidos de materia orgánica (MO), materia inorgánica (MI), proteína bruta (PB), fibra detergente neutro (FDN) y ácido (FDA), lignina, y CSA fueron determinados en un laboratorio comercial (Dairy One, Forage Lab, Ithaca, NY), utilizando metodología establecida (A.O.A.C., 1991; Van Soest et al., 1991).

\section{Proceso Fermentativo}

Para monitorear las características fermentativas y composición química al transcurrir el proceso de ensilamiento, se analizaron muestras del material vegetativo fresco inicial y se abrieron y muestrearon el contenido de tres silos por tratamiento a los $0,4,7,14,21,28$ y 35 $\mathrm{d}$ de fermentación. Las muestras correspondientes a cada periodo de fermentación se sometieron a determinación de $\mathrm{pH}$ y productos de fermentación. Para determinar el $\mathrm{pH}$, se mezclaron $50 \mathrm{~g}$ de cada muestra con $450 \mathrm{ml}$ de agua destilada ( $\mathrm{pH} 7.0$ ) y se agitó en una máquina homogeneizadora por dos minutos. El extracto acuoso resultante se filtró a través de gasa de tela y el filtrado se utilizó para medir el $\mathrm{pH}$, realizado con un medidor equipado con electrodo, estandarizado para $\mathrm{pH} 4$ a 7 utilizando soluciones amortiguadoras comerciales. La determinación de productos de fermentación: ácido láctico, $\mathrm{AL}$; ácido acético, $\mathrm{AA}$; ácido propiónico, AP; y ácido butírico, $\mathrm{AB}$; nitrógeno amoniacal y $\mathrm{N}-\mathrm{NH}_{3} / \mathrm{N}$ Total se realizó en el laboratorio comercial previamente citado. Los datos experimentales referentes a $\mathrm{pH}$ y productos de fermentación se analizaron conforme a un diseño completamente aleatorizado (DCA) con un arreglo factorial $2 \times 7$. El análisis estadístico se llevó a cabo mediante el Modelo Lineal General (GLM) de SAS. Para comparar las diferencias entre los tratamientos individuales, se realizó la prueba de Tukey (SAS, 2004).

\section{Estabilidad Aeróbica}

Para evaluar la EA impartida por ambos tratamientos, después de $35 \mathrm{~d}$ de fermentación se abrieron microsilos de cada tratamiento por triplicado. Se colocaron $500 \mathrm{~g}$ del ensilaje en recipientes de poliestireno, parcialmente envueltos con bolsas de plástico y se expuso 
al aire durante cinco días. La temperatura se revisó cada seis horas durante cinco días con termómetros colocados en la masa del ensilaje. Se determinó el $\mathrm{pH}$ del ensilaje después de $0,1,3$ y $5 \mathrm{~d}$ de exposición aeróbica como descrito anteriormente. Los datos experimentales para temperatura en esta prueba se analizaron conforme a un diseño de parcelas divididas utilizando el procedimiento de Análisis de Modelos Mixtos (proc mixed) de SAS. Las diferencias entre los tratamientos individuales se sometieron a separación de medias de cuadrado mínimos (SAS, 2004). Los datos experimentales de $\mathrm{pH}$ observados en la determinación de EA se analizaron del mismo modo que los datos de temperatura, excepto que se utilizaron cuatro días de exposición $(0$, $1,3,5)$ al aire.

\section{Consumo Voluntario}

Para determinar el CV en ambos experimentos se utilizaron, en un solo periodo, seis ovinos machos nativos de tipo cárnico de un año de edad aproximadamente y de peso vivo (PV) $34.17 \pm 6.94 \mathrm{~kg}$. Se alojó cada cordero en una jaula provista de un comedero doble. Se alimentaron tres animales con cada una de las dos dietas experimentales, durante la prueba de 10 días de duración, abarcando cinco días para adaptación a la jaula, y la rutina experimental y cinco días de recolección de datos comparativos. Para la preparación de los ensilajes se llenaron manualmente 10 bolsas plásticas de $208 \mathrm{~L}$ de capacidad con GTN, con adición de un inóculo (cinco bolsas - T2) o sin dicha adición (cinco bolsas - T1). Las bolsas se cerraron al vacío utilizando una aspiradora y se dejaron para fermentar durante 35 d. En ambos experimentos, una bolsa del T1 y otra del T2 aportaron ensilaje suficiente para alimentar los animales durante dos días. Ambas dietas experimentales tenían en común un 50\% de heno de gramíneas tropicales naturalizadas (HGTN) y $50 \%$ de GTN fermentadas con BPAL (T2) o sin BPAL (T1). La alimentación con el ensilaje y el heno se realizó diariamente a las 6:00 am, ofreciendo los dos componentes de la dieta por separado en los dos compartimientos del comedero doble, a razón de 3\% del PV en base seca (BS). El material rechazado fue recolectado y pesado diariamente luego de 24 horas en el comedero. Durante todo el experimento se le suministró agua ad libitum. Para ambos experimentos los datos experimentales de CV se analizaron conforme a un DCA con tres repeticiones por tratamiento. El análisis estadístico se realizó mediante el GLM de SAS (2004). Se calculó y expresó el CV del ensilaje también en relación al forraje ofrecido (ensilaje + heno) y en relación al ofrecimiento de ensilaje. 


\section{RESULTADOS Y DISCUSIÓN}

\section{Experimento con Inóculo Comercial 1}

Las GTN utilizadas en este experimento mostraron un $\mathrm{pH}$ inicial con media de 5.75 y contenidos porcentuales de MS, 35.54\%; MI, $14.02 \%$; MO, $85.98 \%$ (100-MI); CSA, 0.15\%; y PB, 6.05\%. Referente a los componentes de paredes celulares se determinaron valores porcentuales de FDN, 69.58\%; FDA, 51.82\%, hemicelulosa, 17.76\% (FDNDFA) y lignina $6.52 \%$ (Cuadro 1). Esta composición de las GTN antes de ensilarse se asemeja a las obtenidas en estudios previos con gramíneas tropicales, que se caracterizan por concentraciones bajas y variables de CSA y altas de paredes celulares (Wilkinson, 1983; Van Soest, 1994; Rodríguez et al., 2001).

\section{Proceso Fermentativo}

La acidez, medida inversamente por el $\mathrm{pH}$, fue menor aunque no significativamente después de cuatro días de ensilamiento en GTN ensiladas sin inóculo ( $\mathrm{T} 1,4.65)$, al compararse con el tratamiento con inóculo (T2, 4.36) (Cuadro 2). Sin embargo, a los siete días la diferencia a favor de $\mathrm{T} 1$ fue significativa ( $\mathrm{P}<0.05,4.14$ vs. 4.71$)$. No se observaron diferencias significativas en $\mathrm{pH}$ entre tratamientos después de los siete días de fermentación y no se mantuvo ninguna de las tempranas ventajas citadas. Se verificó una interacción de tratamiento por día de fermentación $(\mathrm{P}<0.001)$. El único caso cuando se acercó el $\mathrm{pH}$ a 4.2, que representa la acidez recomendada para definir un ensilaje estable y de alta calidad (Breirman y Ulvelsi, citados por McCollough, 1978) fue el de $\mathrm{T} 1$ a los siete días de fermentación. Los resultados presentes concuerdan con los de otros experimentos realizados con ensilamiento

CuADRo 1.-Composición química y pH inicial de gramineas tropicales naturalizadas ensiladas en microsilos con y sin Inóculo Comercial 1.

\begin{tabular}{lcc}
\hline Componente $^{1}$ & Media & Desviación Estándar \\
\hline $\mathrm{pH}$ & 5.75 & 0.07 \\
Composición Química (\%) & & \\
$\quad$ Materia seca & 35.54 & 0.06 \\
Materia inorgánica & 14.02 & 1.38 \\
Proteina bruta & 6.05 & 0.86 \\
Fibra detergente neutro & 69.58 & 3.05 \\
Fibra detergente ácido & 51.82 & 1.34 \\
Lignina & 6.52 & 1.17 \\
Carbohidratos solubles en agua & 0.15 & 0.18 \\
\hline
\end{tabular}

${ }^{1}$ Media de tres repeticiones. 
CuADRo 2.-Efecto del tratamiento y día de fermentación sobre el $p H$ y los productos de fermentación de GTN ensiladas con y sin Inóculo Comercial 1.

\begin{tabular}{|c|c|c|c|c|c|c|c|}
\hline \multirow[b]{2}{*}{ Característica $^{1}$} & \multirow[b]{2}{*}{ Día } & \multicolumn{2}{|c|}{ Tratamiento ${ }^{2}$} & \multicolumn{4}{|c|}{ Probabilidad $(\mathrm{P}>\mathrm{F})$} \\
\hline & & 1 & 2 & $\mathrm{EEM}^{3}$ & $\mathrm{~T}^{4}$ & $\mathrm{D}^{5}$ & $\mathrm{~T}^{*} \mathrm{D}^{6}$ \\
\hline \multirow[t]{6}{*}{$\mathrm{pH}$} & $\begin{array}{l}0 \\
4\end{array}$ & $\begin{array}{l}5.77 \\
4.65\end{array}$ & $\begin{array}{l}5.68 \\
4.36\end{array}$ & 0.008 & 0.033 & 0.001 & 0.001 \\
\hline & 7 & $4.14 \mathrm{~b}$ & $4.71 \mathrm{a}$ & & & & \\
\hline & 14 & 4.51 & 4.60 & & & & \\
\hline & 21 & 4.45 & 4.54 & & & & \\
\hline & 28 & 4.50 & 4.49 & & & & \\
\hline & 35 & 4.39 & 4.38 & & & & \\
\hline
\end{tabular}

Productos de Fermentación (\%)

\begin{tabular}{|c|c|c|c|c|c|c|c|}
\hline \multirow[t]{7}{*}{ Ácido láctico } & 0 & $0.132 \mathrm{~b}$ & $0.172 \mathrm{a}$ & \multirow[t]{7}{*}{0.201} & \multirow[t]{7}{*}{0.006} & \multirow[t]{7}{*}{0.001} & \multirow[t]{7}{*}{0.001} \\
\hline & 4 & 0.948 & 1.065 & & & & \\
\hline & 7 & $1.134 \mathrm{a}$ & $0.585 \mathrm{~b}$ & & & & \\
\hline & 14 & $0.475 \mathrm{a}$ & $0.096 \mathrm{~b}$ & & & & \\
\hline & 21 & $0.050 \mathrm{~b}$ & $0.143 \mathrm{a}$ & & & & \\
\hline & 28 & 0.144 & 0.136 & & & & \\
\hline & 35 & 0.147 & 0.115 & & & & \\
\hline \multirow[t]{6}{*}{ Ácido acético } & $\begin{array}{l}0 \\
4\end{array}$ & $\begin{array}{l}0.172 \\
0.390\end{array}$ & $\begin{array}{l}0.192 \\
0.471\end{array}$ & \multirow[t]{6}{*}{0.349} & \multirow[t]{6}{*}{0.614} & \multirow[t]{6}{*}{0.001} & \multirow[t]{6}{*}{0.506} \\
\hline & 7 & 0.404 & 0.416 & & & & \\
\hline & 14 & 0.552 & 0.636 & & & & \\
\hline & 21 & 0.591 & 0.655 & & & & \\
\hline & 28 & 1.702 & 1.499 & & & & \\
\hline & 35 & 1.086 & 1.059 & & & & \\
\hline \multirow[t]{6}{*}{ Ácido propiónico } & 0 & 0.000 & 0.003 & \multirow[t]{6}{*}{0.023} & \multirow[t]{6}{*}{0.518} & \multirow[t]{6}{*}{0.001} & \multirow[t]{6}{*}{0.891} \\
\hline & $\begin{array}{l}4 \\
7\end{array}$ & 0.028 & 0.021 & & & & \\
\hline & 14 & 0.077 & 0.118 & & & & \\
\hline & 21 & 0.114 & 0.085 & & & & \\
\hline & 28 & 0.231 & 0.229 & & & & \\
\hline & 35 & 0.142 & 0.203 & & & & \\
\hline \multirow[t]{7}{*}{ Ácido butírico } & 0 & 0.034 & 0.484 & \multirow[t]{7}{*}{0.948} & \multirow[t]{7}{*}{0.946} & \multirow[t]{7}{*}{0.001} & \multirow[t]{7}{*}{0.681} \\
\hline & 4 & 0.887 & 1.041 & & & & \\
\hline & 7 & 2.772 & 2.894 & & & & \\
\hline & 14 & $6.708 \mathrm{~b}$ & $10.27 \mathrm{a}$ & & & & \\
\hline & 21 & 9.114 & 7.672 & & & & \\
\hline & 28 & 17.27 & 18.07 & & & & \\
\hline & 35 & 12.94 & 15.35 & & & & \\
\hline
\end{tabular}

${ }^{1}$ Media de tres repeticiones.

${ }^{2}$ Medias con diferentes letras en la misma fila tienen diferencia significativa bajo la prueba de Tukey.

${ }^{3}$ Error estándar de las medias.

${ }^{4}$ Efecto de tratamiento (1= Control, $2=$ Inóculo)

${ }^{5}$ Efecto de día de fermentación.

${ }^{6}$ Interacción entre tratamiento y día de fermentación. 
Cuadro 2.-(Continuación) Efecto del tratamiento y dia de fermentación sobre el pH y los productos de fermentación de GTN ensiladas con y sin Inóculo Comercial 1.

\begin{tabular}{|c|c|c|c|c|c|c|c|}
\hline \multirow[b]{2}{*}{ Característica $^{1}$} & \multirow[b]{2}{*}{ Día } & \multicolumn{2}{|c|}{ Tratamiento ${ }^{2}$} & \multicolumn{4}{|c|}{ Probabilidad $(\mathrm{P}>\mathrm{F})$} \\
\hline & & 1 & 2 & $\mathrm{EEM}^{3}$ & $\mathrm{~T}^{4}$ & $\mathrm{D}^{5}$ & $\mathrm{~T}^{*} \mathrm{D}^{6}$ \\
\hline \multirow[t]{6}{*}{$\mathrm{N}-\mathrm{NH}_{3}$} & 0 & 0.000 & 0.000 & 0.003 & 0.113 & 0.208 & 0.807 \\
\hline & 7 & 0.002 & 0.000 & & & & \\
\hline & 14 & 0.002 & 0.000 & & & & \\
\hline & 21 & 0.014 & 0.013 & & & & \\
\hline & 28 & 0.013 & 0.020 & & & & \\
\hline & 35 & 0.011 & 0.033 & & & & \\
\hline \multirow[t]{7}{*}{$\mathrm{NH}_{3} / \mathrm{N}$-Total } & 0 & 0.000 & 0.000 & 3.704 & 0.469 & 0.285 & 0.807 \\
\hline & 4 & 0.000 & 0.000 & & & & \\
\hline & 7 & 0.237 & 0.000 & & & & \\
\hline & 14 & 0.197 & 0.000 & & & & \\
\hline & 21 & 1.694 & 1.615 & & & & \\
\hline & 28 & 1.536 & 2.364 & & & & \\
\hline & 35 & 1.340 & 3.940 & & & & \\
\hline
\end{tabular}

\footnotetext{
${ }^{1}$ Media de tres repeticiones.
} Tukey.

${ }^{2}$ Medias con diferentes letras en la misma fila tienen diferencia significativa bajo la prueba de

${ }^{3}$ Error estándar de las medias.

${ }^{4}$ Efecto de tratamiento $(1=$ Control, $2=$ Inóculo $)$

${ }^{5}$ Efecto de día de fermentación.

${ }^{6}$ Interacción entre tratamiento y día de fermentación.

de gramíneas en ambiente tropical, donde se ha demostrado que la adición de inóculos de bacterias ácido lácticas disminuye el pH durante los primeros días de la fermentación, pero este efecto desaparece después de un lapso que ha variado entre experimentos (Rodríguez, 1996). La concentración de AL fue menor $(P<0.05)$ en el ensilaje fermentado sin inóculo microbiano (T1) a los 0 y 21 días, pero mayor $(\mathrm{P}<0.05)$ a los $7 \mathrm{y}$ $14 \mathrm{~d}$ de fermentación relativo a T2, mientras las diferencias a favor de $\mathrm{T} 2$ a los $4 \mathrm{~d}$ y a favor de $\mathrm{T} 1$ a los 28 y $35 \mathrm{~d}$ no resultaron significativas (Cuadro 2). La interacción de tratamiento por día fue significativa $(\mathrm{P}<$ 0.001). En fin, el patrón de efectos de los tratamientos fue errático. En solo dos casos se observaron concentraciones de AL mayores de 1\% (T2 a los $4 \mathrm{~d}$ y T1 a los $7 \mathrm{~d}$ ). Estos resultados contrastan con la guía de que un contenido de AL de $1.5 \%$ en BS sea considerado como el mínimo requerido en un ensilaje de alta calidad, o que da indicios de una fermentación homoláctica (Breirman y Ulvelsi; citados por McCollough, 1978). Por otro lado, Bates et al. (1989) argumentaron que la concentración ideal de AL de una buena fermentación es de aproximadamente $3.0 \%$. Las hierbas de climas tropicales típicamente tienen menor concentra- 
ción de CSA que las de clima templado, lo que no es ideal para lograr una fermentación láctica adecuada (Titterton y Bareeba, 2000). El bajo contenido de CSA y de AL, resulta en ensilajes con altos valores de $\mathrm{pH}$ (Vendramini et al., 2010). En la investigación de Rodríguez (1996) con ensilaje de sorgo forrajero en clima tropical, la inoculación con BAL incrementó el contenido de AL durante los primeros $14 \mathrm{~d}$ de fermentación. En el presente caso el contenido de AA no difirió significativamente entre ambos tratamientos a través del periodo fermentativo (Cuadro 2). Sin embargo, el efecto de día de fermentación fue significativo $(\mathrm{P}<$ 0.001 ), en virtud de una marcada tendencia ascendente con el tiempo hasta alcanzar concentraciones máximas de AA luego de $28 \mathrm{~d}$ para luego disminuir hasta el día 35. Los contenidos de AA y AL presentes concuerdan con los de estudios previos que mostraron alto contenido de AA y bajo contenido de AL en ensilajes tropicales (Catchpoole y Henzel, 1971). La observación de Oude Elferink et al. (2000) de que L. buchneri tiene la habilidad de convertir el ácido láctico en ácido acético podría explicar en parte la alta producción de este después del día 7 y hasta el día 28 de fermentación. Se ha fijado la concentración ideal de ácido acético en ensilaje de pastos tropicales en menos de 3.0\%, lo cual es ampliamente mayor que los valores presentes, pero se formó más AA que $\mathrm{AL}$, tal vez por ocurrir una fermentación heteroláctica debido a la baja concentración de CSA. Vendramini et al. (2010) obtuvieron concentraciones de ácido láctico y ácido acético parecidas a las presentes al ensilar hierbas en climas tropicales, e indicaron que sería por tratarse de una fermentación heteroláctica. Los niveles de los ácidos grasos volátiles $\mathrm{AP}$ y $\mathrm{AB}$ no difirieron significativamente entre tratamientos con excepción de $\mathrm{AB}$ a los $14 \mathrm{~d}$. (Cuadro 2). La concentración de $\mathrm{AP}$ fue en aumento $(\mathrm{P}<0.001)$ durante los primeros $28 \mathrm{~d}$ del periodo de fermentación para luego descender a los $35 \mathrm{~d}$, sobre todo en T1. La media de $\mathrm{AB}$ de $7.10 \%$ en $\mathrm{BS}$ representa un valor inexplicable y que excede grandemente lo recomendado de menos de un 1\% (McCollough, 1978). Investigaciones más recientes indican que una alta concentración de $\mathrm{AB}$ en el ensilaje ( $>0.5 \%$ de $\mathrm{MS}$ ) se debe a una indeseable fermentación clostridial (Kung y Shaver, 2001). Ensilajes con alto contenido de AB son por lo general bajos en valor nutritivo y tienden a presentar niveles elevados de FDA y FDN, porque muchos de sus nutrientes solubles han sido degradados y ha ocurrido pérdida de MS. Además, tales ensilajes generalmente son de bajo nivel de energía digerible y sus proteínas están extensamente degradadas, resultando en un aumento en la fracción nitrogenada no proteica (NNP). Así mismo, Kung y Stokes (2001) concluyen que los altos niveles de $\mathrm{AB}$ presentes en los ensilajes hechos de forrajes bajos en contenido de azúcar o demasiado húmedos $(<30 \%$ de MS) podrían ser resultado de extensa degradación de proteína. Sin 
embargo, estas consideraciones no bastan para justificar los exagerados niveles de $\mathrm{AB}$ arrojados por el análisis de los ensilajes presentes. El contenido de $\mathrm{N}$-amoniacal fue numéricamente $(\mathrm{P}>0.05)$ menor en GTN ensiladas sin aditivo a los días 28 y 35 de fermentación (Cuadro 2). En ambos tratamientos, la concentración $\mathrm{N}-\mathrm{NH}_{3}$ fue prácticamente nula hasta el día 14 de fermentación para luego aumentar durante el resto del periodo de fermentación en T2, pero sólo hasta el día 21 en T1. Este resultado es indicativo de una mayor hidrólisis de compuestos nitrogenados en ensilaje con inóculo de BAL pero siempre a bajo nivel en general. Según el criterio $\mathrm{N}-\mathrm{NH}_{3} / \mathrm{N}$-Total, el $\mathrm{N}$ contribuido en forma de $\mathrm{NH}_{3}$ llegó a constituir un máximo de 1.69\% del N-Total en T1 (a los 21 días) y $3.94 \%$ en T2 (a los 35 d), sin diferencias significativas (Cuadro 2).

\section{Estabilidad Aeróbica}

El deterioro aeróbico de ensilajes ocurre debido al metabolismo de azúcares residuales y ácidos orgánicos por microorganismos (e.g., bacterias aeróbicas, levaduras, hongos) y este proceso puede ser detectado por aumentos en temperatura y pH (Spolestra et al., 1988). En el experimento presente se observó un aumento en el $\mathrm{pH}(\mathrm{P}<0.05)$ en ensilajes inoculados con BAL y expuestos a condiciones aeróbicas durante cinco días (de 4.38 a 4.55) y al compararse con ensilajes sin aditivo hubo diferencia significativa $(\mathrm{P}<0.05)$ a los 3 y $5 \mathrm{~d}$ (Cuadro 3 ). Si bien, los cambios decrecientes en la acidez fueron de pequeña magnitud, se verificaron efectos significativos de los factores tratamientos $(\mathrm{P}<0.015)$ y día de fermentación $(\mathrm{P}<0.022)$ mientras la interacción de ambos se acercó a la significación $(\mathrm{P}<0.061)$. La temperatura de los ensilajes expuestos al aire no demostró diferencias entre tratamientos $(P>0.05)$, pero sí las hubo entre horas $(P<0.001)$, pero limitadas mayormente a cambios ocurridos durante las primeras 12 horas (Cuadro 3). En conclusión, el ensilaje de GTN producido bajo ambos tratamientos fue estable durante cinco días bajo condiciones aeróbicas. En un estudio previo se observó que la adición de inóculos bacterianos mejoró las características fermentativas, pero no la EA del ensilaje cuando se comparó con ensilajes sin aditivos (Rodríguez, 1996). Esta respuesta difiere de los resultados presentes en el primer punto pero concuerda con respecto al segundo. Sin embargo, en aquel estudio se utilizó sorgo forrajero, un forraje con alto contenido de CSA y menor contenido de paredes celulares que las GTN. Lindgren et al. (1985) encontraron que, en ambientes templados, forrajeras ensiladas con inóculos microbianos conteniendo BAL sufrieron fermentacion homoláctica predominantemente. Este proceso reduce las pérdidas energéticas durante la fase de almacenamiento, pero puede aumentar el deterioro, una vez el ensilaje 
CuADRo 3.-Efecto del tratamiento y día de exposición aeróbica sobre el pH y la temperatura de GTN ensiladas con y sin Inóculo Comercial 1.

\begin{tabular}{|c|c|c|c|c|c|c|c|}
\hline \multirow[b]{2}{*}{ Componente ${ }^{1}$} & & \multicolumn{2}{|c|}{ Tratamiento $^{2}$} & \multicolumn{4}{|c|}{ Probabilidad $(\mathrm{P}>\mathrm{F})$} \\
\hline & & 1 & 2 & $\mathrm{EEM}^{3}$ & $\mathrm{~T}^{4}$ & $\mathrm{D}^{5}$ & $\mathrm{~T}^{*} \mathrm{D}^{6}$ \\
\hline & (Día) & & & & & & \\
\hline \multirow[t]{4}{*}{$\mathrm{pH}$} & 0 & 4.40 & 4.38 & 0.003 & 0.015 & 0.022 & 0.061 \\
\hline & 1 & 4.50 & 4.50 & & & & \\
\hline & 3 & $4.39 \mathrm{~b}$ & $4.52 \mathrm{a}$ & & & & \\
\hline & 5 & $4.42 \mathrm{~b}$ & $4.55 \mathrm{a}$ & & & & \\
\hline \multicolumn{8}{|c|}{ Temperatura $\mathrm{C}^{\circ}$ (Hora) } \\
\hline & 0 & 25.56 & 26.11 & 0.592 & 0.165 & 0.001 & 0.922 \\
\hline & 6 & 26.48 & 26.48 & & & & \\
\hline & 12 & 27.22 & 27.22 & & & & \\
\hline & 24 & 27.41 & 27.41 & & & & \\
\hline & 30 & 27.41 & 27.41 & & & & \\
\hline & 48 & 27.22 & 27.41 & & & & \\
\hline & 72 & 27.22 & 27.59 & & & & \\
\hline & 96 & 27.41 & 27.41 & & & & \\
\hline & 120 & 27.41 & 27.22 & & & & \\
\hline
\end{tabular}

${ }^{1}$ Media de tres repeticiones en Base Seca.

${ }^{2}$ Medias con diferentes letras en la misma fila tienen diferencia significativa bajo la prueba de Tukey.

${ }^{3}$ Error estándar de las medias.

${ }^{4}$ Efecto de tratamiento (1= Control, $2=$ Inóculo)

${ }^{5}$ Efecto de día de fermentación/hora de exposición aeróbica.

${ }^{6}$ Interacción entre tratamiento y día de fermentación/hora de exposición aeróbica.

se expone al aire. Rust et al. (1989) señalaron que el aumento en la producción de AL mediante fermentaciones homolácticas podría resultar en ensilajes menos estables aeróbicamente. Pitt (1990) demostró que los AA y AP tienen propiedades bacteriostáticas o micostáticas, por lo que pueden contribuir a la EA de los ensilajes. Kung y Stokes (2001) comentan que un ensilaje con alto contenido de $\mathrm{AB}$ podría ser muy estable cuando se expone al aire, aunque tenga un $\mathrm{pH}$ bastante alto. Por otro lado, Kung (2005) argumenta que el AB causado por la actividad de clostridios es uno de los agentes de mayor actividad anti-hongos producidos en el ensilaje. Asimismo, los ensilajes con bajo contenido de AL, pero un contenido de AA mayor de $1 \%$, son indicativos de fermentaciones pobres pero pueden ser estables a condiciones aeróbicas.

\section{Consumo Voluntario}

Se observó un mayor consumo total (CT) y consumo de ensilaje (CE) en el tratamiento con aditivo (Figura 1) por márgenes de 154.3 y 178.3 $\mathrm{g} / \mathrm{d}$, respectivamente. Al contrario, el consumo de heno $(\mathrm{CH})$ fue $24.1 \mathrm{~g} / \mathrm{d}$ menor en el tratamiento inoculado relativo al control (563.8 vs. 587.9 


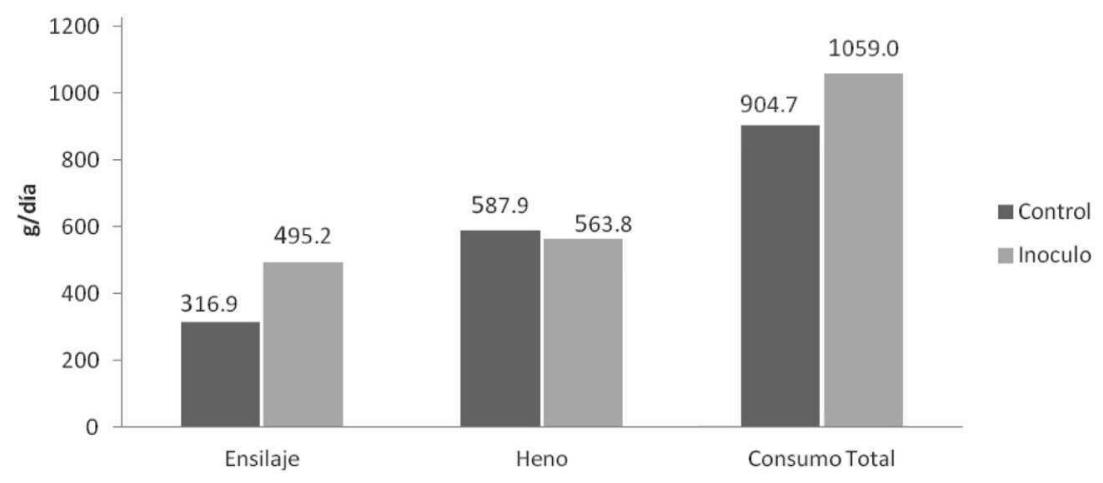

Figura 1. Consumo total e individual de ensilaje con o sin Inóculo Comercial 1 y de heno de gramíneas tropicales naturalizadas.

$\mathrm{g} / \mathrm{d}$ ), aunque las diferencias entre tratamientos no fueron significativas. $\mathrm{La}$ observada disminución en el $\mathrm{CE}$ relativo al $\mathrm{CH}$ no tiene una explicación obvia en ausencia de datos específicos sobre los productos de fermentación en los ensilajes usados en esta prueba in vivo. Aunque no se dispone de dichos datos en estos ensilajes, en la medida en que podrían ser aplicables, los resultados obtenidos con microsilos no revelaron indicios de composición química problemática para un buen CV. Kung y Stokes (2001) asociaron ensilajes con altas cantidades de AA y con bajos consumos de MS. Kung y Shaver (2001) señalaron que altas concentraciones de amoníaco y de $\mathrm{AB}$ suelen ser de baja aceptación animal, pero esto puede deberse a la presencia de concentraciones significativas de otros productos de la descomposición, tales como aminas, que reducen el consumo del animal. Church et al. (2002) concluyeron que un alto $\mathrm{pH}$ junto con un alto porcentaje de $\mathrm{AB}$ crea condiciones óptimas para la proliferación de ciertos tipos de clostridios. Estos clostridios fermentan compuestos de NNP, con liberación de amoníaco y la formación de olores desagradables y posiblemente toxicidad. Buchanan-Smith (1990) concluyó que un ensilaje con alto porcentaje de $\mathrm{AA}(>1 \%)$ sin incrementos en los valores de otros constituyentes, reduce la palatabilidad y por lo tanto el CV. La relación de ensilaje consumido a ensilaje ofrecido (CE/EO) fue mayor para el tratamiento inoculado (97.45\%) comparado con el control $(62.85 \%)$, lo que indica una mejor aceptación por parte de los animales del ensilaje inoculado versus el no inoculado (Figura 2). También la relación de CE/CT fue mayor para el tratamiento con inoculación (46.79\%) relativo al control ( $34.55 \%$ ), lo que constituye otro criterio indicativo de la relativa aceptación animal en ambos casos. 


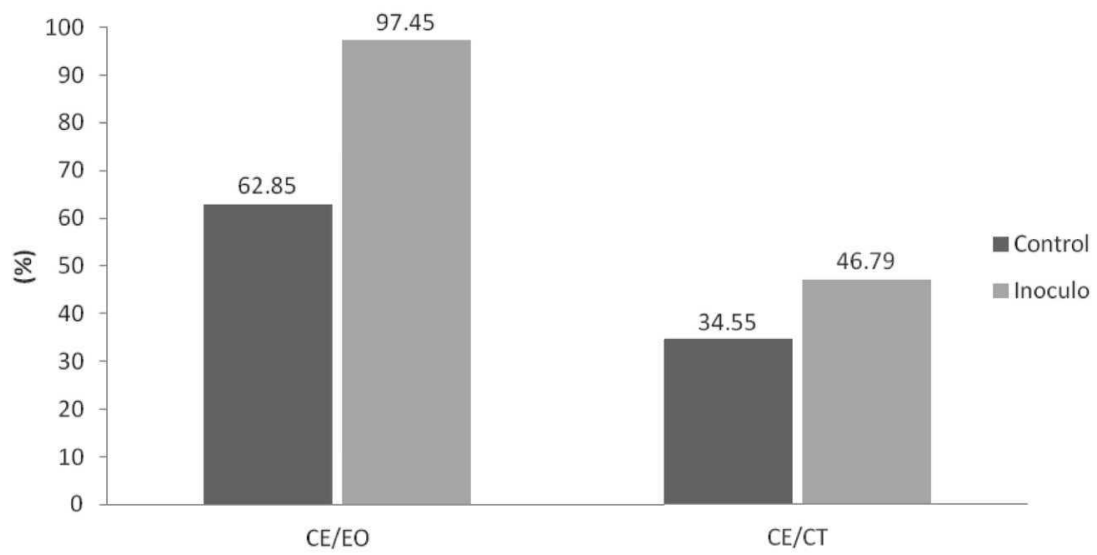

FIGURA 2. Relación del consumo de ensilaje GTN con o sin Inóculo Comercial 1(CE) con el ensilaje ofrecido (EO) y con el consumo total (CT) expresado como porcentaje.

\section{Experimento con Inóculo Comercial 2}

En este estudio las GTN usadas tuvieron un $\mathrm{pH}$ medio inicial de 6.10 y contenidos porcentuales de MS, $25.78 \%$; MI, $15.15 \%$; MO, $84.85 \%$ (100-MI); CSA, 0.53\%; PB, 6.67\%; FDN, 67\%; FDA, 52.90\%; Hemicelulosa, $14.10 \%$ (FDN-FDA) y lignina $7.47 \%$ (Cuadro 4). Una comparación del $\mathrm{pH}$ y la composición química inicial de las GTN de ambos experimentos indica que las GTN del experimento 1 tuvieron un $\mathrm{pH}$ más bajo (5.75) con una diferencia de 0.35 unidades en la escala de $\mathrm{pH}$. Las GTN del experimento 1, también presentaron mayor contenido de MS (35.53\%) superando el valor del experimento 2 por casi 10 unidades porcentuales. Van Soest (1994) argumenta que el porcentaje adecuado

CuADRo 4.-Composición química y $p H$ inicial de gramíneas tropicales naturalizadas ensiladas con y $\sin$ Inóculo Comercial 2.

\begin{tabular}{lrc}
\hline Componente $^{1}$ & Media & Desviación Estándar \\
\hline pH & 6.10 & 0.07 \\
Composición Química (\%) & & \\
Materia seca & 25.78 & 0.32 \\
Materia inorgánica & 15.15 & 0.63 \\
Proteína bruta & 6.67 & 0.25 \\
Fibra detergente neutro & 67.00 & 1.27 \\
Fibra detergente ácido & 52.90 & 0.40 \\
Lignina & 7.47 & 0.66 \\
Carbohidratos solubles en agua & 0.53 & 0.20 \\
\hline
\end{tabular}

${ }^{1}$ Media de tres repeticiones. 
de MS en un forraje para ensilar fluctúa entre 25 y 35\%, de modo que el valor observado en este caso podría ser justamente adecuado o posiblemente marginalmente inadecuado. Sin embargo, los contenidos iniciales de MI, PB, FDN, FDA y lignina fueron similares en BS en ambos experimentos. Resultó sorprendente el contenido de MI tan alto y hasta un poco más en este caso que en el primer experimento, en ausencia de obvia contaminación de GTN con suelo en el segundo experimento. El contenido de CSA fue mayor en el segundo que en el primer experimento ( 0.53 vs. $0.15 \%$ ), pero ambos valores están bastante por debajo del contenido ideal (3\%) (Wilkinson citado por Church et al., 2002).

\section{Proceso Fermentativo}

Las GTN ensiladas con adición del Inóculo Comercial 2 demostraron valores de $\mathrm{pH}$ menores durante todo el proceso de ensilamiento ( $\mathrm{P}>0.05$ ) y una media menor $(\mathrm{P}<0.0001)$, de 5.23 , en comparación con el de $\mathrm{T} 1$ (control) de 5.57. Aun así hubo variación suficiente para resultar en una interacción de tratamiento por día de fermentación $(\mathrm{P}=0.008)$ En ambos tratamientos el $\mathrm{pH}$ disminuyó progresivamente al trascurrir los $35 \mathrm{~d}$ de fermentación $(\mathrm{P}<0.001$ ) (Cuadro 5) y la diferencia entre los dos tratamientos aumentó. Ninguno de los tratamientos logró ensilaje con $\mathrm{pH}$ menor o igual a 4.2, el pH recomendado para definir un ensilaje como estable. El valor final de $\mathrm{pH}$ para T2 (4.77) comenzó a acercarse a dicho valor, pero menos que los $\mathrm{pH}$ finales obtenidos con los ensilajes en el experimento anterior (4.39 y 4.38), tal vez producto del mayor contenido inicial de MS en las GTN ensiladas en ese caso.

$\mathrm{El}$ T2 demostró una temprana ventaja en la concentración de $\mathrm{AL}$ $(\mathrm{P}<0.05)$ a los 4 y $7 \mathrm{~d}$ de fermentación respecto al control, pero solo alcanzó a $0.554 \%$, para luego disminuir abruptamente y seguir con un valor inferior al de T1 durante el resto del periodo de fermentación, con excepción del día 21, resultando en una interacción de tratamiento por día de fermentación ( $\mathrm{P}=0.002)$. El hecho que la media de T2 $(0.26 \%)$ superó $(\mathrm{P}<0.05)$ a la de T1 $(0.10 \%)$ no es muy ilustrativo. En ambos tratamientos, el porcentaje de AL disminuyó después del día 7 de fermentación, probablemente debido a la falta de carbohidratos para uso de las BAL. Otro factor contribuyente podría ser la utilización de AL como sustrato por parte de otras integrantes de la microflora. En experimentación relacionada, Rodríguez (1996) también encontró que inocular sorgo forrajero con BAL incrementó la concentración de $\mathrm{AL}$ en los primeros 14 días de fermentación.

En el tratamiento con el inóculo comercial, durante los primeros siete días de fermentación, el pH disminuyó de 6.04 a 5.02 comparado con el tratamiento sin inocular en que descendió de 6.15 a 5.49. Durante los mismos días de fermentación, en la GTN inoculada el porcentaje de 
CuADRo 5.-Efecto del tratamiento y día de fermentación sobre el pH y los productos de fermentación de GTN ensiladas con y sin Inóculo Comercial 2.

\begin{tabular}{|c|c|c|c|c|c|c|c|}
\hline \multirow[b]{2}{*}{ Característica $^{1}$} & \multirow[b]{2}{*}{ Día } & \multicolumn{2}{|c|}{ Tratamiento $^{2}$} & \multirow[b]{2}{*}{$\mathrm{EEM}^{3}$} & \multicolumn{3}{|c|}{ Probabilidad $(\mathrm{P}>\mathrm{F})$} \\
\hline & & 1 & 2 & & $\mathrm{~T}^{4}$ & $\mathrm{D}^{5}$ & $\mathrm{~T}^{*} \mathrm{D}^{6}$ \\
\hline \multirow[t]{6}{*}{$\mathrm{pH}$} & $\begin{array}{l}0 \\
4\end{array}$ & $\begin{array}{l}6.15 \\
5.55 \mathrm{a}\end{array}$ & $\begin{array}{l}6.04 \\
5.32 \mathrm{~b}\end{array}$ & 0.073 & $<.001$ & $<.001$ & 0.008 \\
\hline & 7 & $5.49 \mathrm{a}$ & $5.02 \mathrm{~b}$ & & & & \\
\hline & 14 & $5.56 \mathrm{a}$ & $5.25 \mathrm{~b}$ & & & & \\
\hline & 21 & $5.57 \mathrm{a}$ & $5.21 \mathrm{~b}$ & & & & \\
\hline & 28 & $5.45 \mathrm{a}$ & $4.98 \mathrm{~b}$ & & & & \\
\hline & 35 & $5.21 \mathrm{a}$ & $4.77 \mathrm{~b}$ & & & & \\
\hline
\end{tabular}

Productos de Fermentación (\%)

Ácido láctíco

$\begin{array}{rllllll}0 & 0.020 & 0.021 & 0.101 & <.001 & <.001 & 0.002 \\ 4 & 0.148 \mathrm{~b} & 0.426 \mathrm{a} & & & & \\ 7 & 0.127 \mathrm{~b} & 0.554 \mathrm{a} & & & & \\ 14 & 0.083 & 0.049 & & & & \\ 21 & 0.015 & 0.049 & & & & \\ 28 & 0.160 & 0.124 & & & & \\ 35 & 0.206 & 0.123 & & & & \end{array}$

Ácido acético

$\begin{array}{rll}0 & 0.037 & 0.042 \\ 4 & 0.199 & 0.124 \\ 7 & 0.212 & 0.214 \\ 14 & 0.324 & 0.180 \\ 21 & 0.239 & 0.268 \\ 28 & 0.646 & 0.484 \\ 35 & 0.595 \mathrm{a} & 0.278 \mathrm{~b}\end{array}$

Ácido propiónico

$\begin{array}{rllllll}0 & 0.000 & 0.008 & 0.003 & 0.002 & 0.001 & 0.400 \\ 4 & 0.078 & 0.004 & & & & \\ 7 & 0.098 & 0.012 & & & & \\ 14 & 0.112 \mathrm{a} & 0.029 \mathrm{~b} & & & & \\ 21 & 0.071 & 0.052 & & & & \\ 28 & 0.196 \mathrm{a} & 0.074 \mathrm{~b} & & & & \\ 35 & 0.168 & 0.082 & & & & \end{array}$

Ácido butírico

$\begin{array}{rllllll}0 & 0.000 & 0.000 & 0.020 & 0.651 & <.001 & 0.032 \\ 4 & 0.216 \mathrm{a} & 0.047 \mathrm{~b} & & & & \\ 7 & 0.180 & 0.140 & & & & \\ 14 & 0.487 & 0.404 & & & & \\ 21 & 0.746 & 0.386 & & & & \\ 28 & 0.743 & 0.671 & & & & \\ 35 & 0.688 \mathrm{~b} & 0.854 \mathrm{a} & & & & \end{array}$

${ }^{1}$ Media de tres repeticiones en Base Seca.

${ }^{2}$ Medias con diferentes letras en la misma fila tienen diferencia significativa bajo la prueba de Tukey.

${ }^{3}$ Error estándar de las medias.

${ }^{4}$ Efecto de tratamiento ( $1=$ Control, 2= Inóculo)

${ }^{5}$ Efecto de día de fermentación.

${ }^{6}$ Interacción entre tratamiento y día de fermentación. 
Cuadro 5.-(Continuación) Efecto del tratamiento y día de fermentación sobre el pH y los productos de fermentación de GTN ensiladas con y sin Inóculo Comercial 2.

\begin{tabular}{|c|c|c|c|c|c|c|c|}
\hline \multirow[b]{2}{*}{ Característica $^{1}$} & \multirow[b]{2}{*}{ Día } & \multicolumn{2}{|c|}{ Tratamiento $^{2}$} & \multirow[b]{2}{*}{$\mathrm{EEM}^{3}$} & \multicolumn{3}{|c|}{ Probabilidad $(\mathrm{P}>\mathrm{F})$} \\
\hline & & 1 & 2 & & $\mathrm{~T}^{4}$ & $\mathrm{D}^{5}$ & $\mathrm{~T} * \mathrm{D}^{6}$ \\
\hline \multirow[t]{6}{*}{$\mathrm{NH}_{3}$} & $\begin{array}{l}0 \\
4\end{array}$ & $\begin{array}{l}0.018 \\
0.035\end{array}$ & $\begin{array}{l}0.017 \\
0.024\end{array}$ & 0.001 & 0.020 & 0.002 & 0.807 \\
\hline & 7 & 0.030 & 0.015 & & & & \\
\hline & 14 & 0.029 & 0.029 & & & & \\
\hline & 21 & 0.022 & 0.014 & & & & \\
\hline & 28 & 0.021 & 0.007 & & & & \\
\hline & 35 & 0.007 & 0.000 & & & & \\
\hline \multirow[t]{6}{*}{$\mathrm{NH}_{3} / \mathrm{N}$-Total } & $\begin{array}{l}0 \\
4\end{array}$ & $\begin{array}{l}2.128 \\
4.237\end{array}$ & $\begin{array}{l}2.051 \\
2.871\end{array}$ & 1.500 & 0.021 & 0.002 & 0.796 \\
\hline & 7 & 3.560 & 1.879 & & & & \\
\hline & 14 & 3.431 & 3.505 & & & & \\
\hline & 21 & 1.696 & 2.550 & & & & \\
\hline & 28 & 2.530 & 0.855 & & & & \\
\hline & 35 & 0.859 & 0.000 & & & & \\
\hline
\end{tabular}

${ }^{1}$ Media de tres repeticiones en Base Seca. Tukey.

${ }^{2}$ Medias con diferentes letras en la misma fila tienen diferencia significativa bajo la prueba de

${ }^{3}$ Error estándar de las medias.

${ }^{4}$ Efecto de tratamiento $(1=$ Control, $2=$ Inóculo $)$

${ }^{5}$ Efecto de día de fermentación.

${ }^{6}$ Interacción entre tratamiento y día de fermentación.

AL aumentó de $0.02 \%$ hasta $0.55 \%$, lo que podría ser la causa principal del citado descenso de $\mathrm{pH}$ del T2. Por contraste, en el T1 sin inocular el porcentaje de AL sólo aumentó de 0.02 a 0.12 durante el mismo lapso de fermentación.

El contenido de AA (Cuadro 5) aumentó progresivamente durante los primeros $28 \mathrm{~d}$ del periodo de fermentación $(\mathrm{P}<0.001)$, y hubo diferencia numérica a favor del tratamiento control sobre T2 a los días 14, 28 y 35 de fermentación, cuando alcanzó significación ( 0.59 vs. $0.28 \%$ ) $(\mathrm{P}<0.05)$. Ambos tratamientos resultaron en contenidos de AA por debajo del nivel de $1 \%$ que podría aportar algo de importancia a la preservación del ensilaje.

La comparación de las medias de contenido de $\mathrm{AP}$ favoreció $(\mathrm{P}=$ 0.0002 ) al tratamiento control (sin inóculo) sobre T2 (0.11 vs. $0.04 \%$ ). Al transcurrir los días de fermentación, el contenido del mismo aumentó $(\mathrm{P}<0.05)$ en ambos tratamientos, pero siempre con ventaja de $\mathrm{T} 1$ sobre T2 y sólo en el T1 sobrepasó el límite recomendado por Kung y Stokes (2001) en ensilajes de gramíneas $(<0.1 \% / \mathrm{BS})$. Referente al contenido de $\mathrm{AB}$, se observó un aumento progresivo $(\mathrm{P}<0.001)$ a través 
del periodo fermentativo en los ensilajes de ambos tratamientos. A los cuatro días de fermentación se obtuvo una diferencia $(\mathrm{P}<0.05)$ a favor de $\mathrm{T} 1(0.216$ vs. $0.047 \%)$ mientras que a los $35 \mathrm{~d}$ el T2 tuvo mayor valor ( $0.854 \%$ vs. $0.688 \%)$, de modo que el efecto de tratamiento fue indeciso y no significativo $(\mathrm{P}=0.651)$ y se verificó una interacción $(\mathrm{P}<0.032)$ de tratamiento por día de fermentación. Estos resultados analíticos referentes a $\mathrm{AB}$ son mucho más razonables que los obtenidos en el primer experimento. McCollough (1978) recomendó un nivel de $\mathrm{AB}$ menor de $1 \%$ en BS en los buenos ensilajes. Investigaciones más recientes (Kung y Shaver, 2001) señalan que una alta concentración de $\mathrm{AB}$ ( $>0.5 \%$ en BS) indica que el ensilaje ha experimentado una fermentación clostridial indeseable y podría tener elevados niveles de FDA y FDN por la degradación de muchos de los nutrientes solubles, con consecuente pérdida de valor nutritivo. Kung y Stokes (2001) argumentan que el contenido de $\mathrm{AB}$ debe ser indetectable en buenos ensilajes de maíz y alfalfa mientras el contenido de AA debe fluctuar de 1 hasta $3 \%$. En cambio, los altos niveles de $\mathrm{AA}(>3$ a $4 \%)$ o $\mathrm{AB}(>0.5 \%)$ en cualquier tipo de ensilaje son indicadores de fermentación menos deseable.

El contenido porcentual de $\mathrm{NH}_{3}$ difirió entre tratamientos $(\mathrm{P}=0.002)$ con medias globales de 0.023 para T1 (no inoculado) y 0.015 para T2. Se observó, para ambos tratamientos, un aumento temprano $(\mathrm{P}<0.05)$ en $\mathrm{NH}_{3}$ hasta el día 4 de fermentación y luego un descenso continuo hasta el día 35 con excepción del día 14 en T2. La proporción $\mathrm{N}-\mathrm{NH}_{3} / \mathrm{N}$ Total fue menor ( $\mathrm{P}=0.0216$ ) en ensilaje inoculado que en el control, 1.83 vs. $2.75 \%$. Estas cifras indican que hubo una baja degradación de proteínas a $\mathrm{NH}_{3}$, aunque el forraje tenía un bajo contenido inicial de las mismas (Cuadro 4). En los ensilajes de maíz, la $\mathrm{NH}_{3}$ normalmente constituye entre el 5 y el $7 \%$ de la PB pero tiende a ser más alta (10 a $15 \%$ ) en ensilaje de gramíneas y alfalfa (Kung y Stokes, 2001).

Al comparar ambos experimentos referentes a algunos de los ácidos orgánicos presentes en los ensilajes, como AL y AA, se notan diferencias importantes. Las GTN ensiladas con inóculo (T2) presentaron mayores porcentajes de AL y AA en el primer experimento que en el segundo ( 0.33 y 0.61 vs. 0.19 y 0.22 , respectivamente). En ambos experimentos el contenido de $\mathrm{AP}$ y $\mathrm{NH}_{3}$ en los ensilajes fue similar. Estas diferencias en concentraciones de los ácidos orgánicos no reflejan el mayor contenido inicial de CSA en las GTN del segundo experimento, sino más bien el mayor contenido inicial de MS en las GTN del primer experimento.

Estabilidad Aeróbica

Al exponer los ensilajes de GTN a condiciones aeróbicas durante cinco días, se registró un pH más ácido $(\mathrm{P}<0.05)$ en T2 que en T1 en cada uno de los cuatro días de observación. Además, se observó una 
tendencia a valores ascendentes con el tiempo en ambos tratamientos, pero la tendencia más acentuada en T2 que en T1 fue suficiente para producir una interacción $(\mathrm{P}<0.045)$ entre tratamiento y día de exposición (Cuadro 6). En la temperatura de los ensilajes expuestos al aire no se encontró diferencias entre tratamientos $(P>0.05)$, pero sí un efecto de las horas de exposición aeróbica $(\mathrm{P}<0.001)$ (Cuadro 6). Es notable que los dos tratamientos cambiaron de orden (mayor o menor) cinco veces durante las nueve observaciones sin resultar en una interacción significativa entre tratamiento y hora $(\mathrm{P}=0.193)$. Las temperaturas finales representan aumentos netos sobre los iniciales de sólo 0.93 y $1.67^{\circ} \mathrm{C}$ en T1 y T2, respectivamente. La buena EA de los ensilajes de ambos tratamientos podría deberse en parte a sus contenidos de ácidos orgánicos, $\mathrm{AA}, \mathrm{AP}$ y $\mathrm{AB}$, pero probablemente estarán involucrados otros compuestos no analizados. Los cambios mínimos en pH y temperatura en ambos tratamientos son típicos de ensilajes de hierbas tropicales (Rodríguez, 1996).

A partir de los estudios con ensilajes inoculados con diferentes bacterias ácido lácticas, homo y heterofermentativas, Danner et al. (2003)

CuADRo 6.-Efecto del tratamiento y día de exposición aeróbica sobre el pH y la temperatura de GTN ensiladas con y sin Inóculo Comercial 2.

\begin{tabular}{lccccccc}
\hline & & \multicolumn{2}{c}{ Tratamiento $^{2}$} & & \multicolumn{3}{c}{ Probabilidad (P>F) } \\
\cline { 3 - 4 } \cline { 7 - 8 } Componente $^{1}$ & (Día) & 1 & 2 & EEM $^{3}$ & $\mathrm{~T}^{4}$ & $\mathrm{D}^{5}$ & $\mathrm{~T}^{*} \mathrm{D}^{6}$ \\
\hline $\mathrm{pH}$ & 0 & $5.21 \mathrm{a}$ & $4.77 \mathrm{~b}$ & 0.0070 & $<.0001$ & $<.0001$ & 0.0446 \\
& 1 & $5.34 \mathrm{a}$ & $4.82 \mathrm{~b}$ & & & & \\
& 3 & $5.40 \mathrm{a}$ & $5.14 \mathrm{~b}$ & & & & \\
& 5 & $5.59 \mathrm{a}$ & $5.32 \mathrm{~b}$ & & & &
\end{tabular}

Temperatura $\mathrm{C}^{\circ}$ (Hora)

\begin{tabular}{rrrrrrr}
0 & 26.29 & 25.74 & 0.2054 & 0.6213 & $<.0001$ & 0.1929 \\
6 & 26.66 & 26.85 & & & & \\
12 & 27.96 & 27.96 & & & & \\
24 & 28.52 & 27.77 & & & & \\
30 & 27.41 & 26.66 & & & \\
48 & 26.66 & 26.48 & & & \\
72 & 26.85 & 27.04 & & & \\
96 & 27.04 & 26.66 & & & \\
120 & 27.22 & 27.41 & & & \\
\hline
\end{tabular}

${ }^{1}$ Media de tres repeticiones. Tukey.

${ }^{2}$ Medias con diferentes letras en la misma fila tienen diferencia significativa bajo la prueba de

${ }^{3}$ Error estándar de las medias.

${ }^{4}$ Efecto de tratamiento $(1=$ Control, 2 = Inóculo)

${ }^{5}$ Efecto de día de fermentación/hora de exposición aeróbica.

${ }^{6}$ Interacción entre tratamiento y día de fermentación/hora de exposición aeróbica. 
concluyeron que la EA del ensilaje es determinada solamente por la concentración de AA. Este ácido actúa como un inhibidor del crecimiento de microorganismos causantes de deterioro aeróbico. Semejante propiedad posee el AP (Merry y Davies, 1999). Danner et al. (2003) observaron que la adición de AA amortiguado no influyó sobre el $\mathrm{pH}$ del ensilaje, pero aumentó la estabilidad aeróbica, y que la adición de AA puro sí disminuyó el pH y también resultó en un claro aumento de la EA. Queda fuera de duda la eficacia preservativa del AA en los ensilajes. Según los citados autores, la EA del ensilaje a un $\mathrm{pH}$ constante depende sólo del tipo y concentración de los ácidos orgánicos.

Si bien esta investigación no se diseñó para comparar los dos aditivos de BAL, es relevante notar que al comparar la EA de los ensilajes de T2 de ambos experimentos, durante cinco días de exposición, el $\mathrm{pH}$ subió finalmente a 5.32 en el segundo experimento contra 4.55 en el primero. Las cifras correspondientes de temperatura del ensilaje a cinco días de exposición muestran escasa diferencia ( 27.41 vs. 27.22 ${ }^{\circ} \mathrm{C}$ ). Los ensilajes control (T1) mostraron valores de $\mathrm{pH}$ a los cinco días de exposición aeróbica de 5.59 y 4.42 en el presente y el anterior experimento, mientras las temperaturas finales fueron 27.22 y $27.41^{\circ} \mathrm{C}$, respectivamente. En ninguno de los dos casos se nota mucho efecto de los inóculos sobre la EA.

\section{Consumo Voluntario}

En la evaluación de los forrajes in vivo, se observó un mayor CT (P>0.05) por un margen de $109.7 \mathrm{~g} / \mathrm{d}$ (1172.3 vs. $1062.6 \mathrm{~g} / \mathrm{d}$ ) (Figura 3) de parte de los ovinos de T1 cuya dieta constó del ensilaje control y HGTN versus los de T2, que recibieron el ensilaje inoculado y HGTN. $\mathrm{Al}$ igual que en el primer experimento, el $\mathrm{CH}$ fue mayor que el $\mathrm{CE}$, pero la diferencia en $\mathrm{CH}$ entre tratamientos fue de sólo $19.7 \mathrm{~g} / \mathrm{d}$ ( $\mathrm{P}>0.05)$. El CE obtenido en el tratamiento control fue $90.0 \mathrm{~g} / \mathrm{d}$ mayor que el del ensilaje inoculado (525.3 vs $435.3 \mathrm{~g} / \mathrm{d}$ ), aunque ninguna de estas diferencias fue significativa. Comparando ambos experimentos, el CV de ensilaje de GTN con inóculo (T2) fue mayor en el experimento 2 (525.3 $\mathrm{g} / \mathrm{d}$ ) versus el experimento 1 ( $495.2 \mathrm{~g} / \mathrm{d})$. Relativo a sus respectivos controles (T1), el CE de T2 lo superó por $43.8 \%$ en la primera oportunidad, mientras al contrario, en la segunda quedó superado por $17.1 \%$ (Figuras 1 y 3 ).

La relación de CE/EO fue mayor en el caso del control sin inocular (92.24\%) comparado con el T2 con ensilaje inoculado (78.25\%). Este resultado indica una mejor aceptación animal del primero (Figura 4). La relación de CE/CT también fue menor para el ensilaje inoculado (40\%) relativo al ensilaje sin inocular (44.8\%), lo que añade evidencia 


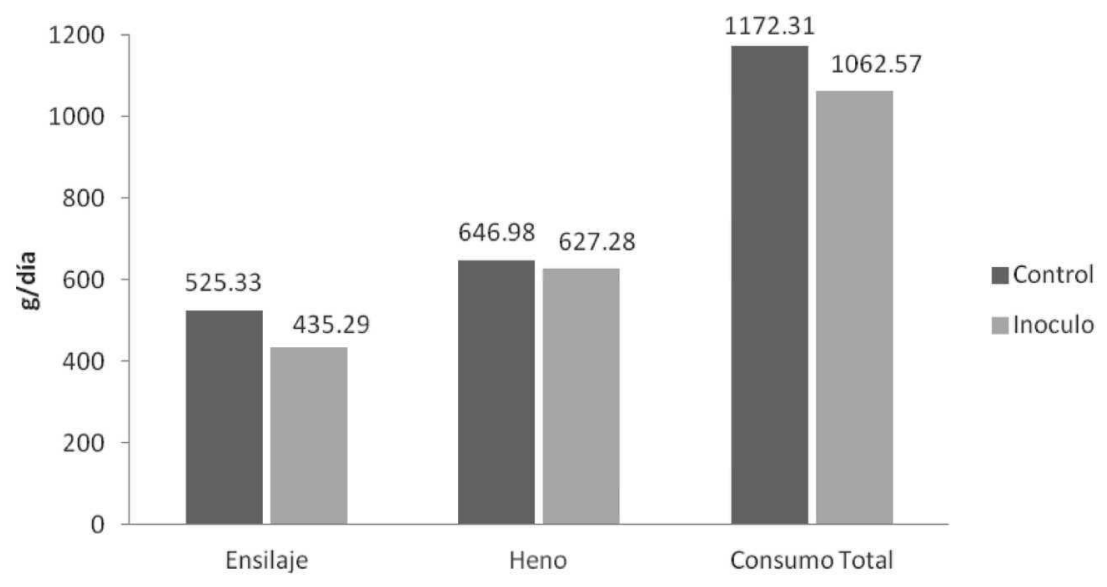

Figura 3. Consumo total e individual de ensilaje con o sin Inóculo Comercial 2 y de heno de gramíneas tropicales naturalizadas.

en apoyo de la mejor aceptación animal del ensilaje control en este experimento (Figura 4).

En esta investigación se logró la producción de buen ensilaje de GTN en microsilos y en mayor cantidad en bolsas de plástico sin el uso de aditivo alguno, a juzgar por los resultados de $\mathrm{pH}$ (experimento 1), EA y CV, aun cuando en el experimento 2, al ensilar GTN más húmedas, el pH y contenido de AL no fueran indicativos de condiciones ideales.

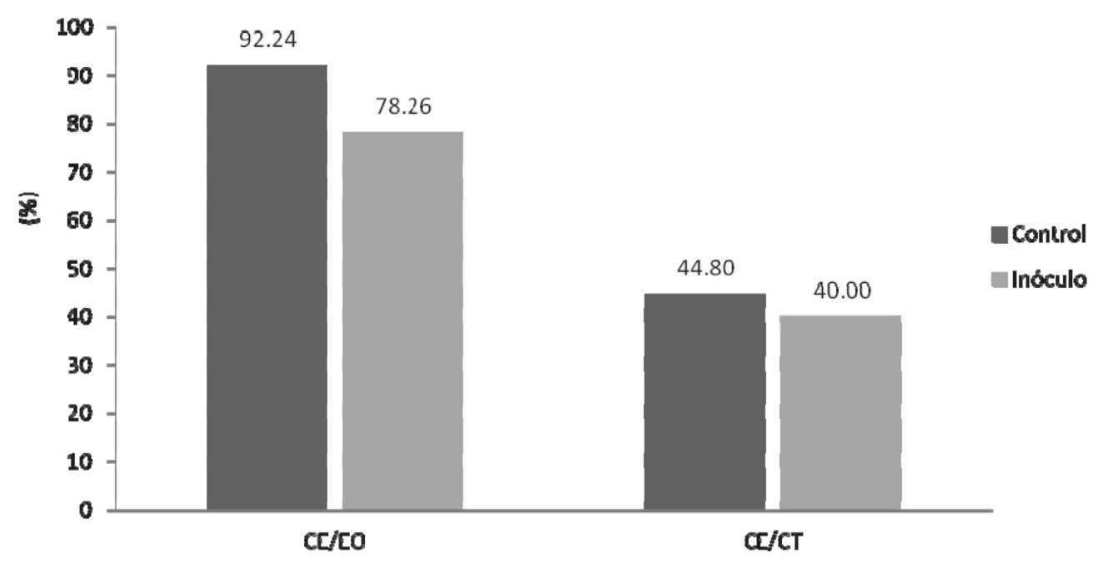

Figura 4. Relación del consumo de ensilaje de GTN con o sin Inóculo comercial 2 (CE) con el ensilaje ofrecido (EO) y con el consumo total (CT) expresadas como porcentajes. 
Frente al aparente éxito de los ensilajes control, tal vez sería difícil que cualquier inóculo de BAL lograra un impacto significativo en mejorar el ensilaje. El inóculo evaluado en el experimento 1 mostró algún efecto beneficioso sobre el CV de ensilaje y de MS total, mientras el inóculo del experimento 2 mejoró el $\mathrm{pH}$ del ensilaje. Estos pueden considerarse los resultados más positivos referentes al uso de los inóculos, pero no se trata de grandes efectos.

\section{CONCLUSIONES}

La utilización de los inóculos comerciales evaluados en esta investigación no evidenció una mejora en las características fermentativas de gramíneas naturalizadas ensiladas en microsilos de laboratorio. En ambos experimentos los ensilajes fermentados en microsilos con y sin la adición de inóculo de BAL se mostraron estables a condiciones aeróbicas durante cinco días de exposición. En el experimento 1 no hubo diferencias significativas en CE, CH ni CT (ensilaje más heno) entre los tratamientos, pero el CV del ensilaje con inóculo llevó una ventaja absoluta y también relativa al ofrecimiento del mismo (CE/EO) sobre el ensilaje control ( $97.45 \%$ vs. $62.85 \%$ ). En el experimento 2 al ofrecer a los ovinos dietas con $50 \%$ de HGTN y $50 \%$ de ensilaje de GTN fermentado con o sin inóculo por 35 d, hubo un mayor CV de HGTN que de las GTN fermentadas, mientras las diferencias en $\mathrm{CH}, \mathrm{CE}$ y CT a favor del control fueron relativamente pequeñas.

\section{LITERATURA CITADA}

Adesogan, A. T., 2006. Factors affecting corn silage quality in hot and humid climates. En 17th Florida Ruminant Nutrition Symposium. University of Florida. Gainesville. pp. 108-127.

Adesogan, A. T., N. Krueger, M. B. Salawu, D. B. Dean y C. R. Staples, 2004. The influence of treatment with dual purpose bacterial inoculants or soluble carbohydrates on the fermentation and aerobic stability of bermudagrass. J. Dairy Sci. 87:34073416 .

A.O.A.C. (Association of Official Analytical Chemists), 1991. Official methods of analysis, 13th ed. Washington, D. C.

Bates, D. B., W. E. Kunkle, C. G. Chambliss y R. P. Cromwell, 1989. Effect of dry matter and additives on bermudagrass and rhizoma peanut round bale silage. J. Prod. Agric. 2:91.

Buchanan-Smith, J. G., 1990. An investigation into palatability as a factor responsible for reduced intake of silage by sheep. Anim. Prod. 50:253-260.

Catchpoole, V. R. y E. F. Henzell, 1971. Silage and silage making from tropical herbage species. Herbage Abst. 41:3.

Church, D. C., W. G. Pond y K. R. Pond, 2002. Fundamentos de nutrición y alimentación animal. $2^{\text {nd }}$ ed. Editorial Limusa, S.A. Mexico. pp. 335-340 
Danner, H., M. Holzer, E. Mayrhuber y R. Braun, 2003. Acetic acid increases stability of silage. Appl. Environ. Microbiol. 69 (1):562.

Kung, J. R., 2005. Aerobic Stability of Silages. Proc. of the Conference on Silage for Dairy Farms. Harrisburg, PA.

Kung, L. y R. Shaver, 2001. Interpretation and use of silage fermentation analysis reports. Wisconsin Forage Team, Focus on Forage 13 (13):20-28.

Kung, L. y M. R. Stokes, 2001. Analysing Silage for Fermentation End Products. http:/ ag.udel.edu/anfs/faculty/kung/articles/analyzing_silages_for_fermentati.htm

Lindgren, S. E., K. L. Petterson, A. Johnson, P. Lingvail y A. Kasoersson, 1985. Silage inoculation- selected strain, temperature, wilting and practical applications. Swed. J. Agric. Res. 15:19.

Martínez, J. L., 1998. Efecto de la aplicación de aditivos comerciales sobre las características fermentativas y estabilidad aeróbica de forrajeras ensiladas en ambientes tropicales. M.S.Tesis, Universidad de Puerto Rico, Recinto de Mayagüez.

Martínez, J. L., A. A. Rodríguez, F. Arias, R. Macchiavelli y E. Riquelme, 1999. Características fermentativas y establidad aeróbica de sorgo granífero (Sorghum bicolor) ensilado en Puerto Rico bajo varias dosis de inóculo comercial. J. Agric. Univ. P.R. $83(3-4): 135-151$.

McCullough, M. E., 1978. Silage: some general considerations. In: M.E. McCullough (Ed). Fermentation of silage- A Review. National Feed Ingredients Association. West Des Moines, IA. pp. 3-28.

McDonald, P., A. R. Henderson y S. J. Heron, 1991. The Biochemistry of Silage. $2^{\text {nd }}$ ed. Cholcombe Publ. Cambriam Printers Ltd., Aberystwyth, U.K. pp. 184-236.

Merry, J. y D. R. Davies, 1999. Propionibacteria and their role in the biological control of aerobic spoilage in silage. A Review. Inra. Elsevier, Lait. 79:149-164.

Muck, R. E., L. E. Moser y R. E. Pitt, 2003. Post-harvest factors affecting ensiling. En D. R. Buxton, R. E. Muck, y J. H. Harrison (Eds.). Silage Science and Technology. American Society of Agronomy. Madison, WI: pp. 251-304.

Namihira, T., N. Shinzato, H. Akamine, H. Maekawa y T. Matsui, 2009. Influence of nitrogen fertilization on tropical-grass silage assessed by ensiling process monitoring using chemical and microbial community analyses. J. Appl. Microbiol. (108):19541965.

Oude Elferink, S. J. W. H., J. Krooneman, J. C. Gottschal, S. F. Spoelstra, F. Faber y F. Driehuis, 2000. Anaerobic conversion of lactic acid to acetic acid and 1,2 propanediol by Lactobacillus buchneri. Appl. Environ. Microbiol. 67 (1):125-132.

Pitt, R. E., 1990. Silage and hay preservation. Northeast Regional Agricultural Engineering Service. Ithaca, NY. NRAES-5. pp 12-34.

Ranjit, N. K. y L. Kung, Jr., 2000. The effect of Lactobacillus buchneri, Lactobacillus plantarum, or a chemical preservative on the fermentation and aerobic stability of corn silage. J Dairy Sci. 83:526-535.

Rodríguez, A. A., 1996. Studies on the efficiency of a homofermentative lactic acid-producing bacterial inoculant and commercial, plant cell-wall degrading enzyme mixtures to enhance the fermentation characteristics and aerobic stability of forage ensiled in temperature and tropical environments. Ph. D. Dissertation, Michigan State University. East Lansing, MI.

Rodríguez, A., J. Martínez, R. Macchiavelli y E. Riquelme, 2001. Sucesión microbiana, productos de fermentación y estabilidad aeróbica de yerba guinea ensilada con un aditivo conteniendo inóculo de bacterias y enzimas fibrolíticas. J. Agric. Univ. P.R. 85:151-164.

Rust, S. R., M. S. Kim y G. L. Enders, 1989. Effects of a microbial inoculants on fermentation characteristics and nutritive value of corn silage. J. Prod. Agric. 2:235. 
SAS Institute Inc., 2004. SAS/STAT 9.1 User's Guide. SAS Institute, Inc Cary, NC.

Spoelstra, S. F., M. G. Courtin y J. A. C. van Beers, 1988. Acetic acid bacteria can initiate aerobic deterioration of whole crop maize silage. J. Agr. Sci. Camb. 111:127-132.

Titterton, M. y F. B. Bareeba, 2000. Grass and legume silages in the tropics. En L.t'Mannetje, (ed). Silage Making in the Tropics with Particular Emphasis on Smallholders. Food Agric. Org. United Nations, Rome, Italy. p. 43

Van Soest, P. J., J. B. Robertson y B. A. Lewis, 1991. Methods for dietary fiber, neutral detergent fiber and non-starch polysaccharides in relation to animal nutrition. $J$. Dairy Sci. 74:3583-3597.

Van Soest, P. J., 1994. Forage Conservation. En: Nutritional Ecology of the Ruminant. 2nd. Edition. Cornell University Press, Ithaca, NY. pp. 141-151.

Vendramini, J. M. B., A. A. Desogan, M. L. A. Silveira, L. E. Sollenberger, O. C. M. Queiroz y W. F. Anderson, 2010. Nutritive value and fermentation parameters of warm-season grass silage. The Professional Animal Scientist 26 (2):193-200.

Weinberg, Z. G., G. Ashbell, K. K. Bolsen, G. Pahlow, Y. Hen y A. Azreili, 1995. The effect of a propionic acid bacterial inoculant applied at ensiling, with or without lactic acid bacteria, on the aerobic stability of pearl millet and maize silages. J. Appl. Bact. 78 (4):430-436.

Wilkinson, J. M., 1983. Silage made from tropical and temperature crops. I. The ensiling process and its influence on feed value. World Anim. Rev. Jan-March. 